\title{
Australian Journal of Crop Science \\ Rice grain quality as affected by blast-causing agent (Pyricularia oryzae) along with a molecular analysis of blast resistance at Pi5 and Pi-ta loci
}

\author{
Asadollah Ahmadikhah ${ }^{1 *}$, Vahid Khosravi ${ }^{2}$ \\ ${ }^{1}$ Department of Plant Sciences and Biotechnology, Faculty of Life Sciences and Biotechnology, Shahid Beheshti \\ University, Tehran, Iran \\ ${ }^{2}$ Plant Pathology Section, Rice Research Institute, Amol, Mazandarn, Iran
}

*Corresponding author: a_ahmadikhah@sbu.ac.ir

\begin{abstract}
Blast disease is the most devastating disease of rice worldwide, which reduces both quantity and quality of rice production. To assess the effect of fungal agent of blast, Pyricularia oryzae, on some aspects of grain quality of rice, 31 rice cultivars (including 20 local landraces) were evaluated at seedling and post-harvest stages. The cultivars were grown in three replicates in a field surrounded by blast spreader cultivars and at appropriate times blast infection type, grain infection, 100-grain weight and grain quality traits (percentage of broken rice and number of chalky seeds per panicle) were evaluated. For tracking alleles of two major blast resistance genes (including Pi5 and $P$ i-ta) the respective primer pairs were applied in a polymerase chain reaction (PCR) on DNA of the studied cultivars. Evaluation of blast infection type at seedling stage showed that four cultivars were completely resistant, 4 cultivars moderately resistant and 23 cultivars mainly consisted of local landraces were susceptible. Fungal treatment had significant effects on percentages of grain infection and broken rice and not on number of chalky seeds or 100-grain weight. Rice genotypes had significant differences in grain infection and also in 100-grain weight and in two quality traits including percentage of broken rice and number of chalky seeds. Most local landraces showed highest grain infection (14.4-17.6\%) compared to improved modern varieties with lowest grain infection (1.3-2.7\%). Results also showed that genotype by fungal treatment interaction were only significant for grain infection and broken rice. All susceptible cultivars had higher broken rice relative to resistant cultivars (10.5-13.3\% vs. $2.1-4.6 \%)$ after blast infection. Molecular survey showed that most susceptible local landraces carry Pi5 dominant allele, while high-yielding modern cultivars don't carry the allele, indicating that Pi5 does not play a significant role in blast resistance at this time. Furthermore, molecular survey showed that only three cultivars including a local cultivar (Tetep) and two modern ones (IR56, IR24) harbored Pi-ta allele, and Pi-ta explained a high part of variation of blast resistance $\left(R^{2}=53.7 \%\right)$. These results indicate the importance of Pi-ta gene for improving rice blast-resistance and grain quality at blast infection conditions.
\end{abstract}

Keywords: Infection; P. oryzae; Quality; Pi5; Pi-ta; Resistance; Rice.

Abbreviations: ANOVA_analysis of variance, PCR_polymerase chain reaction, HGW_hundred grain weight, MR_moderate resistant, R_resistant, S_susceptible, SES_standard evaluation system, TBE_Tris-Borate-EDTA.

\section{Introduction}

Rice blast disease caused by Pyricularia oryzae Cavara, is the most destructive rice disease worldwide, and also it is the most common disease of both temperate and subtropical areas of East Asia (Bonman, 1991). Even in less blast conducive environments, such as rain-fed lowland rice areas in the sub-tropics, serious epidemics occur where aromatic cultivars are grown (Ou, 1985). The pathogen is most common on leaves or on nodes, neck and panicle branches during the reproductive stage (Bonman, 1992). Blast epidemic causes complete loss of seedling in nursery (Chaudhury et al., 1994). Outbreak of this disease is a serious and recurrent problem, and it is extremely difficult to control in all rice growing regions of the world (Khan et al., 2014). Rice blast epidemics have been reported in several countries, particularly in Asia, typically resulting in 10-50\% yield losses (Loan et al., 2003).
The interaction between host resistance and fungus virulence in the rice blast pathosystem can be explained by the gene-for-gene rule (Flor, 1956, Silue et al., 1992). In most studies (Higashi and Kushibuchi, 1978; Maruyama et al., 1983; Higashi and Saito, 1985; Wang et al., 1994; Nagato and Yoshimura, 1998; Ahn et al., 2000; Hayashi et al., 2004; Zhou et al., 2004; Wu et al., 2005; Gowda et al., 2006; Li et al., 2007,2008 ) it was reported that field resistance to blast is complex and controlled by multiple genes with complementary or additive effects (He et al., 1989). Hostplant resistance based on the gene-for-gene interaction is the most economical and environmentally safe approach to control the disease (Jia et al., 2000). However, the pathogenicity of $M$. grisea isolates is highly variable and sometimes a small section of the virulent isolates spreads rapidly and overcomes resistance genes of rice cultivars 
(Wang et al., 1994; Fukuoka and Okuno, 2001). During the last decade, the genetics of blast resistance has been extensively studied and nearly 40 resistance genes have been identified. Most of the resistance genes are from landraces, of indica subspecies (Rahman et al., 2011). Pi5(t) locus creates a diverse spectrum of resistance to Pyricularia oryzae and it carries genes for blast resistance including Pi3(t) and Piil $(t)$ (Wang et al., 1994; Han, 2001). Pan et al. (2003) mapped Pi5 locus along with Pii, Pi3 and Pil5 on chromosome 9. In a more precise study, Lee et al (2009) narrowed down the gene locus to a $13 \mathrm{Kbp}$ fragment and by sequence analysis showed that the locus consisted of two tightly linked genes, Pi5-1 and Pi5-2, which none of them didn't confer blast resistance when transferred to a susceptible cultivar. However, blast resistance was observed via simultaneous transformation of Pi5-1 and Pi5-2 to susceptible cultivar. These two genes encode proteins with coiled-coli NBS-LRR motifs which are characteristic of $R$ genes. Pi-ta gene is located near the centromere of chromosome 12 and finally was isolated by using map-based cloning method from Japanese cultivar Yashiromochi (Bryan et al., 2000). Pi-ta encodes a cytoplasmic receptor with an NBS motif which seemingly causes induction cycle of AVRpita (a pathogen gene encoding a putative zinc metalloprotease, playing a critical role in triggering Pi-tamediated resistance) to activate defense response in rice. The Pi-ta resistance protein differs by one amino acid from the pi-ta susceptible protein from an indica rice variety (serine to alanine), and by five amino acids from the pi-ta susceptible protein from japonica rice varieties (Bryan et al., 2000).

Rice quality is of great importance for all people involved in producing, processing, and consuming of rice, because it affects the nutritional and commercial value of grains (Koutroubas et al., 20009). But rice infection to P. oryzae reduces both quantity and quality of rice production. In recent years, despite release of rice blast-resistant cultivars and increasing of the area under cultivation of these cultivars, every year a large area of land is devoted still to the cultivation of landrace varieties, because of their suitable quality. With regret to extreme sensitivity of these cultivars to blast disease, farmers forced to frequently use the fungicides for controlling this disease (Mousanejad et al., 2010), which can lead to environmental pollution (Pasha et al., 2013). Though most of the field research on rice blast disease has been conducted in tropical and subtropical environments (Koutroubas et al., 2009), detailed information on the effect of blast disease on seed quality of aromatic rice is limited (Khan et al., 2014). Therefore, the present study was undertaken to assess the effect of blast disease on seed quality traits of aromatic rice and to conduct molecular tracking of blast resistance at Pi5 and Pi-ta loci.

\section{Results}

\section{Seedling stage}

Analysis of variance (ANOVA) showed that the differences between control and blast infection treatments at seedling stage was highly significant for leaf infection type (Table 1), so that leaf infection type under blast infection differed significantly from that under normal condition (their average scores were 0.43 and 3.62 , respectively). The ANOVA also detected highly significant differences among the studied cultivars in leaf infection type at seedling stage (Table 1). Treatment $\times$ genotype interaction was significant for this trait, indicating that different rice cultivars differentially responded to blast infection.

Based on standard evaluation system (SES) rice cultivars were placed into three groups: four cultivars were completely resistant (with scores: 0-2) including Neda, IR56, Tetep and IR24 (international check), 4 cultivars were moderately resistant (with scores: 2.1-3) and 23 cultivars, mainly consisted of local cultivars, were susceptible (with scores: 3.1-5) (Fig. 1).

\section{Whole plant}

Rice cultivars showed different degrees of panicle infection (Fig. 2A). Iranian landraces (such as Domsiah, Deilamani, Tarom_Mahali, Champa and Hasani) and IRRI-originated cultivars (such as IR28 and IR24) showed highest and lowest degrees of blast infection, respectively. The fungus did not cover the whole seed (Fig. 2 B-C) and produced small, inconspicuous, grey to green colonies on seed glumes consisting of short, delicate, conidiophores carrying clusters of conidia at their tips (Fig. $2 \mathrm{D}$ ).

Analysis of variance (ANOVA) showed that fungal treatment had significant effects on rate of grain infection and 100-grain weight (Table 1). Average grain infection under fungal treatment was $10.6 \%$ which was significantly higher than that control condition $(<1.0 \%)$. Average 100 kernal weight under fungal treatment $(2.26 \mathrm{~g})$ was significantly lower than that under control condition ( $2.53 \mathrm{~g}$ ). Average grain weight reduction due to blast infection was $10.7 \%$, and in contrast, percentage of broken rice and chalky grains did not significantly differ between blast treatment and control condition.

Cultivars had significant differences in grain infection, 100 grain weight and also in two quality traits (Table 1). Most local cultivars (including Champa, Domsiah, Sadri etc.) showed highest grain infection (14.4-17.6\%) compared to improved IRRI varieties (including IR56, IR28 and IR24) with low grain infection (1.3-2.7\%) (Fig. 3A). Interaction of genotype $x$ fungal treatment was significant for grain infection, percentage of broken rice and 100-grain weight. Diseased cultivars had higher broken rice than healthy cultivars (10.5-13.3\% vs. 2.1-4.6\%) (Fig. 3B). Furthermore, diseased cultivars had lower 100-grain weight than that of healthy cultivars (2.03-2.26 g vs. 2.37-2.61 g).

\section{Correlation and cluster analysis}

Correlation analysis under blast infection showed that a highly significant positive correlations (from 0.791 to 0.974 ) existed between blast infection score, grain infection rate and number of broken seeds, while a significant mild negative correlations were observed between hundred grain weight with blast infection score and grain infection rate, 0.606 and -0.604 , respectively (Table 2 ). Also, correlation between hundred grain weight and number of broken seeds was significantly negative (-0.641).

Cluster analysis using UPGMA method based on Euclidian distance grouped the studied genotypes into two distinct clusters (Fig. 4). All local Iranian cultivars were placed in first cluster and most improved cultivars (including IRRI-originated 
Table 1. Analysis of variance for leaf infection at seedling stage, grain infection, 100-grain weight and two quality traits at whole plant stage.

\begin{tabular}{|c|c|c|c|c|c|c|}
\hline S.O.V & d.f & Leaf infection & Grain infection & $\begin{array}{c}\text { 100-grain } \\
\text { weight }\end{array}$ & $\begin{array}{c}\text { Percentage of } \\
\text { broken rice }\end{array}$ & $\begin{array}{c}\text { Number of } \\
\text { chalky grains }\end{array}$ \\
\hline Replicate & 2 & $0.01^{\text {ns }}$ & $141.56^{\mathrm{ns}}$ & $11.86^{\text {ns }}$ & $100.63^{\text {ns }}$ & $68.48^{\text {ns }}$ \\
\hline Treatment & 1 & $4.61^{* *}$ & $512.35^{*}$ & $68.33^{*}$ & $426.17^{\mathrm{ns}}$ & $126.25^{\mathrm{ns}}$ \\
\hline Genotype & 30 & $5.32^{* *}$ & $778.71^{* *}$ & $93.44^{* *}$ & $623.37^{* *}$ & $359.37^{*}$ \\
\hline Treatment*genotype & 30 & $4.73^{* *}$ & $483.28^{*}$ & $64.57^{*}$ & $396.71^{*}$ & $217.46^{\mathrm{ns}}$ \\
\hline Error & 123 & 0.190 & 136.44 & 17.63 & 104.92 & 89.43 \\
\hline
\end{tabular}

ns, ${ }^{*}$ and ${ }^{* *}$ : non-significant, significant at $5 \%$ level and significant at $1 \%$ level of probability, respectively.

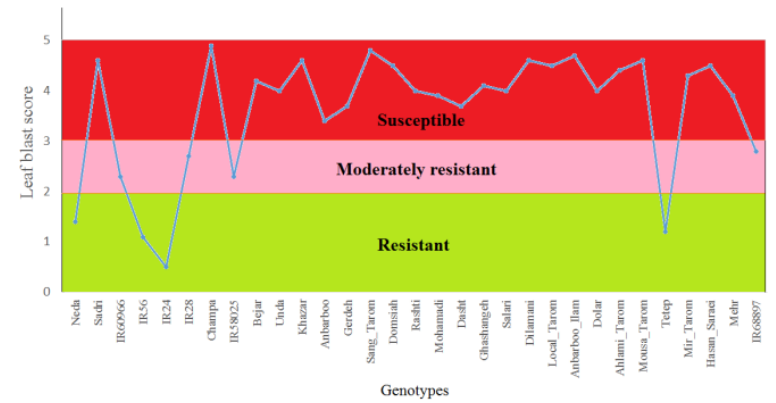

Fig 1. Reaction of the studied genotypes to blast fungus at seedling stage. Leaf blast scores are shown on $Y$ axis and genotype names are shown on $\mathrm{X}$ axis.

Table 2. Survey results of seedling blast reaction and molecular genotyping of the studied cultivars.

\begin{tabular}{|c|c|c|c|c|c|c|c|}
\hline \multirow[t]{2}{*}{ Cultivar } & \multicolumn{2}{|c|}{ Genotype } & \multirow[t]{2}{*}{ Reaction } & \multirow[t]{2}{*}{ Cultivar } & \multicolumn{2}{|c|}{ Genotype } & \multirow[t]{2}{*}{ Reaction } \\
\hline & Pi5 & $P i-t a$ & & & Pi5 & $\begin{array}{c}P i- \\
t a\end{array}$ & \\
\hline Neda & pi5 & pi-ta & $\mathrm{R}$ & Mohamadi & Pi5 & pi-ta & $\bar{S}$ \\
\hline Sadri & Pi5 & $p i-t a$ & $S$ & Dasht & Pi5 & pi-ta & $\mathrm{S}$ \\
\hline IR60966 & pi5 & $p i-t a$ & MR & Ghashangeh & Pi5 & pi-ta & $\mathrm{S}$ \\
\hline IR56 & pi5 & Pi-ta & $\mathrm{R}$ & Salari & Pi5 & pi-ta & $\mathrm{S}$ \\
\hline IR24 & pi5 & Pi-ta & $\mathrm{R}$ & Dilamani & Pi5 & pi-ta & $\mathrm{S}$ \\
\hline IR28 & pi5 & $p i-t a$ & MR & Local_Tarom & Pi5 & pi-ta & $\mathrm{S}$ \\
\hline Champa & Pi5 & $p i-t a$ & $S$ & Anbarboo_llam & Pi5 & pi-ta & $\mathrm{S}$ \\
\hline IR58025 & pi5 & $p i-t a$ & MR & Dolar & Pi5 & pi-ta & $\mathrm{S}$ \\
\hline Bejar & pi5 & $p i-t a$ & $S$ & Ahlami_Tarom & Pi5 & pi-ta & $\mathrm{S}$ \\
\hline Unda & pi5 & $p i-t a$ & $S$ & Mousa_Tarom & Pi5 & pi-ta & $\mathrm{S}$ \\
\hline Khazar & pi5 & $p i-t a$ & $S$ & Tetep & Pi5 & Pi-ta & $\mathrm{R}$ \\
\hline Anbarboo & Pi5 & $p i-t a$ & $S$ & Mir_Tarom & pi5 & pi-ta & $\mathrm{S}$ \\
\hline Gerdeh & Pi5 & $p i-t a$ & $S$ & Hasan_Saraei & Pi5 & pi-ta & $\mathrm{S}$ \\
\hline Sang_Tarom & Pi5 & $p i-t a$ & $S$ & Mehr & Pi5 & pi-ta & $\mathrm{S}$ \\
\hline Domsiah & Pi5 & $p i-t a$ & $S$ & IR68897 & pi5 & pi-ta & $M R$ \\
\hline Rashti & Pi5 & $p i-t a$ & S & & & & \\
\hline
\end{tabular}

S: susceptible, R: resistant, MR: moderately resistant.

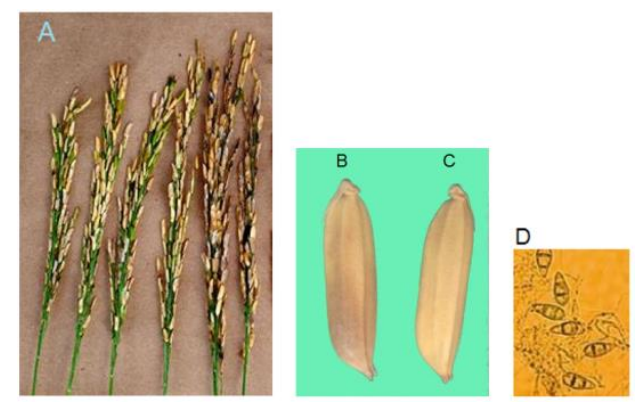

Fig 2. Differential response of rice cultivars to blast infection. (A) Panicle infection of different rice cultivars by $P$. oryzae, (B) an infected seed, (C) an uninfected seed as control, (D) visualization of $P$. oryzae conidia under microscope isolated from infected seed. 
Table 3. Correlation between different traits under blast infection.

\begin{tabular}{|c|c|c|c|c|}
\hline & Leaf blast reaction score & Grain infection rate & Broken seeds & HGW \\
\hline Leaf blast reaction score & 1 & $0.830^{* *}$ & $0.791 * *$ & $-0.606^{*}$ \\
\hline Grain infection rate & & 1 & $0.974 * *$ & $-0.604^{*}$ \\
\hline Broken seeds & & & 1 & $-0.641^{*}$ \\
\hline HGW & & & & 1 \\
\hline
\end{tabular}

HGW: hundred grain weight; $\mathrm{ns}^{*}$ and ${ }^{* *}$ : non-significant, significant and highly significant at $5 \%$ and $1 \%$ level of probability

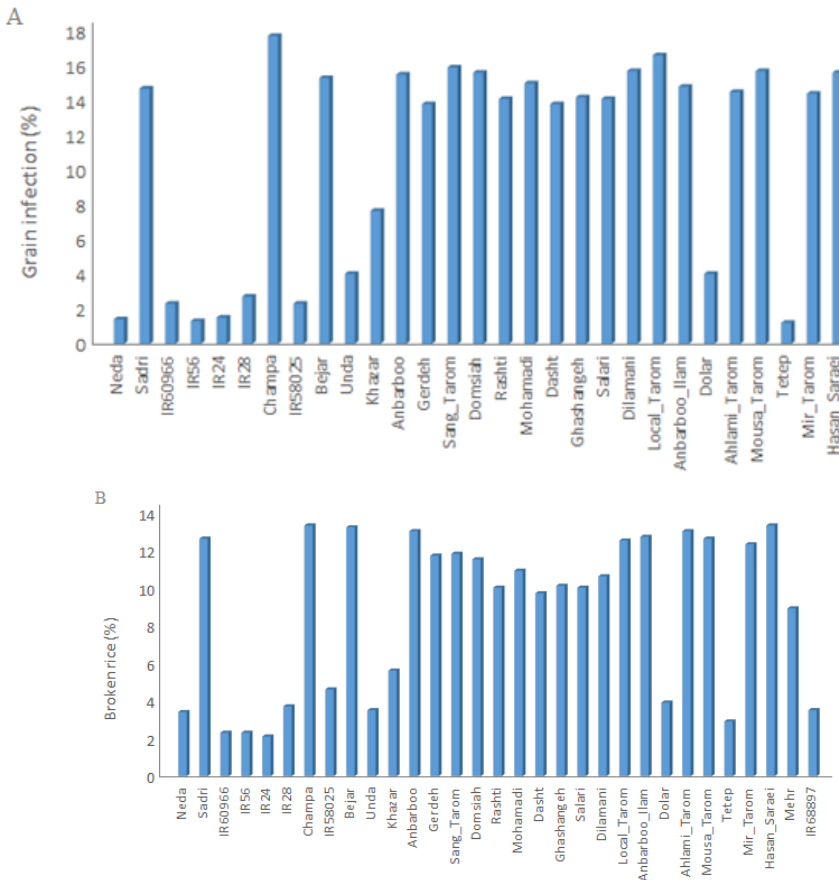

Fig 3. The response of studied cultivars to blast infection. (A) rate of grain infection of rice cultivars to $P$. oryzae, (B) percentages of broken rice as affected by blast fungus in different rice cultivars.

Table 4. The lines and cultivars used in the study.

\begin{tabular}{|c|c|c|c|c|c|}
\hline Symbo & Name & Origin & Symbol & Name & Origin \\
\hline L1 & Neda & Iran, improved & L17 & Mohamadi*† & Iran, local \\
\hline L2 & Sadri*† & Iran, local & L18 & Dasht & Iran, improved \\
\hline L3 & IR60966 & IRRI, improved & L19 & Ghashangeh*† & Iran, local \\
\hline L4 & IR56 & IRRI, improved & L20 & Salari*† & Iran, local \\
\hline L5 & IR24 & IRRI, improved & L21 & Dilamani*† & Iran, local \\
\hline L6 & IR28 & IRRI, improved & L22 & Tarom_Mahali*† & Iran, local \\
\hline L7 & Champa*† & Iran, local & L23 & Anbarboo_llam*十 & Iran, local \\
\hline L8 & IR58025 & IRRI, improved & L24 & Dolar & USA, improved \\
\hline L9 & Bejar*† & Iran, local & L25 & Ahlami_Tarom*† & Iran, local \\
\hline L10 & Unda* & Japon, local & L26 & Mousa_Tarom*+ & Iran, local \\
\hline L11 & Khazar & Iran, improved & L27 & Tetep* & Vietnam, local \\
\hline L12 & Anbarboo*† & Iran, local & L28 & Mir_Tarom*† & Iran, local \\
\hline $\mathrm{L} 13$ & Gerdeh* & Iran, local & L29 & Hasan_Saraei*† & Iran, local \\
\hline L14 & Sang_Tarom*† & Iran, local & L30 & Mehr & Iran, improved \\
\hline L15 & Domsiah*† & Iran, local & L31 & IR68897 & IRRI, improved \\
\hline L16 & Rashti*† & Iran, local & & & \\
\hline
\end{tabular}


A

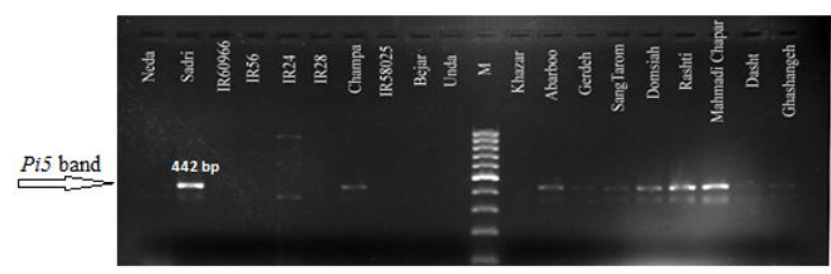

B

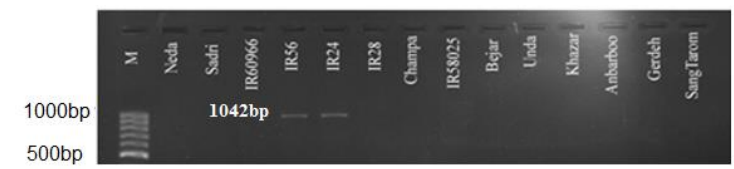

c

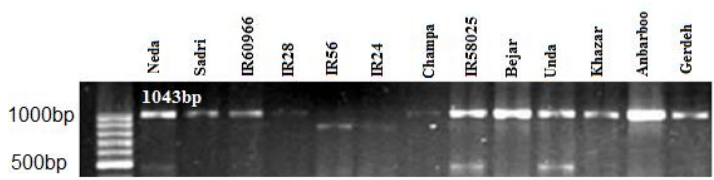

Fig 4. A sample of banding pattern of different rice cultivars using allele-specific primers. (A) Banding pattern using Pi5 specific primers; 442 bp band as expected is amplified in cultivars harboring dominant allele of Pi5. (B) Banding pattern using Pi-ta specific primers; 1042 bp band is amplified only in cultivars harboring dominant allele Pi-ta as expected. (C) Banding pattern using pi-ta specific primers; $1043 \mathrm{bp}$ band is amplified only in cultivars harboring recessive allele pi-ta as expected. Cultivar names are written at top of each lane. M: molecular size marker.

Table 5. Primes for tracking alleles of Pi-ta gene.

\begin{tabular}{lcc}
\hline Primer name & Sequence $\left(5^{\prime}-.3^{\prime}\right)$ & Reference \\
\hline YL155-F & AGCAGGTTATAAGCTAGGCC & Wang et al. (2007) \\
YL183-R & AGCAGGTTATAAGCTAGCTAT & \\
YL187-R & CTACCAACAAGTTCATCAAA & \\
\hline
\end{tabular}

Note: Combination of YL155-F and YL183-R amplifies a DNA fragment of 1042 bp in Pi-ta harboring cultivars (dominant specific allele) and combination of YL155-F and YL187-R amplifies a DNA fragment of 1043 bp in pi-ta harboring cultivars (recessive specific allele).

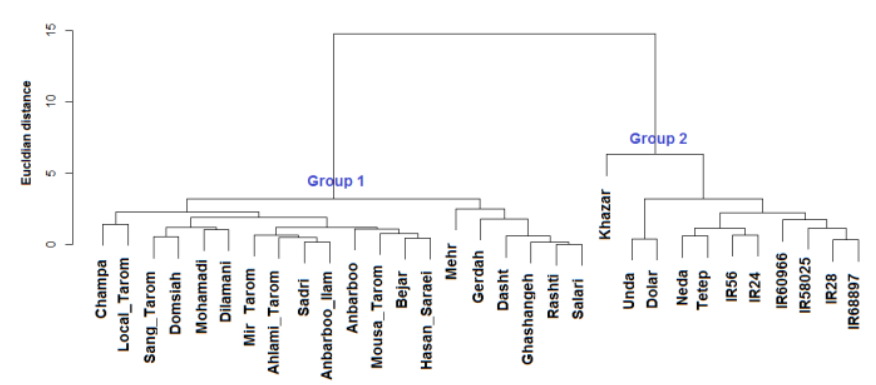

Fig 5. A dendrogarm of the studied cultivars produced using UPGMA method based on Euclidian distances.

originated cultivars) along with two local cultivars, Tetep and Unda were placed in second cluster.

\section{Prediction of disease resistance by gene-specific markers}

\section{Assessment of cultivars at Pi5 locus}

Screening for Pi5 locus using specific primers showed that most of Iranian local rice cultivars carry this locus, including Champa, Anbarboo, Gerdeh, Sadri, Domsiah, Deilamani etc. (Fig. 5 A, Table 3). As seen in Table 3, high-yielding cultivars such as Neda, IR28 and Khazar, and IRRI cultivars do not carry the dominant Pi5 allele. Association analysis showed that Pi5 allele had a positive correlation with disease severity (leaf blast scores) and explained only a low part of its variation $\left(R^{2}=29.2 \%\right)$.

\section{Assessment of cultivars at Pi-ta locus}

Screening for Pi-ta locus showed that most of the studied cultivars do not carry the dominant allele of this gene (Fig. 5 B and Fig. 5 C, Table 3). Only three out of 31 cultivars including IR56, IR24 and Tetep harbored dominat Pi-ta allele. Association analysis showed that Pi-ta allele had a negative 
correlation with disease severity (leaf blast scores) and explained a high part of its variation $\left(R^{2}=53.7 \%\right)$.

\section{Discussion}

In this research we evaluated blast-reaction of local aromatic and improved rice cultivars at seedling and panicle stages, and also we evaluated the effect of the disease on some quality traits. Most local aromatic Iranian cultivars including Domsiah, Hasani, Champa, Tarom_Mahali were blastsusceptible in blast nursery. Abedi et al. (2012) by evaluating blast-resistance-related traits at seedling stage, also reported that Iranian local cultivars such as Domsiah, Deilamani, Tarom_Mahali and Hasani were blast-susceptible. At panicle stage, Iranian landraces and IRRI-originated cultivars showed highest and lowest degrees of blast infection, respectively. In the work of Khan et al. (2014) also differential blast-response of studied cultivars in panicle infection was reported.

Fungal treatment also significantly reduced 100-grain weight ( $10.7 \%$ loss) which is comparable to that of reported previously (Koutroubas et al., 2009) where inoculation of $P$. oryzae resulted in lower grain weight compared to the noninoculated plants (11\% in 2002 and $7 \%$ in 2003). In contrast, percentage of broken rice and chalky grain were not significantly differed between treated and control conditions. In the work of Hai et al. (2007) also the percentage of broken rice and chalky grain were not significantly different among treated and non-treated conditions. Most local cultivars showed highest grain infection (14.4-17.6\%) compared to improved IRRI varieties (1.3-2.7\%). Previous works also indicated differential response of rice cultivars to blast infection at vegetative or reproductive stages (Hai et al., 2007; Koutroubas et al., 2009; Pasha et al., 2013; Khan et al., 2014). Interestingly, diseased cultivars had higher broken rice, and also they had lower 100-grain weight than that of healthy cultivars. In the work of Khan et al. (2014) two out of 3 studied aromatic cultivars had significant lower grain weight under blast infection relative to control condition.

Results of molecular assessment showed that most highyielding cultivars such as Neda, Khazar, and IRRI cultivars do not carry the dominant Pi5 allele. However, most local Iranian cultivars carried Pi5 allele. Despite this, they are blast-susceptible, as we showed a low correlation between blast-resistance and presence of Pi5 allele. This finding indicates that Pi5 do not play, at present, a significant role in rice blast-resistance. Tracking Pi5 using linked markers such as JJ80-T3, Abedi et al. (2012) also reported the existence of Pi5 gene in some local Iranian cultivars such as Domsiah, Deilamani, Tarom_Mahali and Hasani. Despite the finding that most local Iranian cultivars harbor Pi5 dominant allele, they are blast-susceptible. In contrast to our results, Kawasaki-Tanaka and Fukuta (2014) reported that blast resistance of nearly all Japanese varieties is originated from Pish and Pik-s genes. Therefore the genes can be alternatively used for improving rice blast-resistance. As revealed in this research, for example, cv. Tetep carries Pi5 dominant allele, but resistance of the cultivar seemingly is due to existence of Pi-ta gene in its genome. Therefore, in the limits of this research, it may be concluded that Pi5 had not a significant effect on blast-resistance. However, other research suggested the existence of another major gene, Pik-h, in cultivar Tetep (Barman et al., 2004).

Results of molecular survey also showed that only two IRRI-originated cultivars (e. g. IR56 and IR24) plus a local landrace, Tetep, carried Pi-ta allele. As our results showed, IR56 and IR24 had complete resistance to blast at seedling stage that could be related to the existence of Pi-ta major gene. Other reports also confirmed the resistance of IR24 at seedling stage (Pasha et al., 2013, Mousanejad et al., 2010). Early reports indicated that the Pi-ta gene was introgressed into elite cultivars from landrace indica cultivars (e.g. Tetep and Taducan) for the control of infection by races of $M$. oryzae that contain AVR-Pita (Jia and Martin, 2008; Kiyosawa, 1967; Moldenhauer et al., 1990). Pi-ta locus has been effectively utilized to prevent blast disease for the past 40 years and is still effectively used in more rice cultivation areas (Kiyosawa 1967, Jia et al., 2004, Barman et al., 2004, Jia and Valent 2007). The results of our research supported by other researches, indicate the importance of Pi-ta gene for improving both rice blast resistance and grain quality at blast infection conditions.

\section{Conclusion}

Based on the research findings it can be concluded that most local landraces are susceptible to blast disease and hence, show a low grain quality (e.g. high grain infection and broken rice) under blast infection compared to modern resistant varieties. Furthermore, most local landraces carry Pi5 dominant and pi-ta receive alleles. Since two modern cultivars (IR56, IR24) and one local cultivar (Tetep) harbored $\mathrm{Pi}$-ta allele, molecular breeders can use these cultivars in their breeding programs for improving new blast resistant cultivars via marker-aided selection (MAS). The results of our research indicate the importance of Pi-ta gene for improving blast resistance and consequently for improving grain quality at blast infection conditions.

\section{Materials and methods}

\section{Plant material}

In this research 31 rice lines and cultivars were selected to assess blast infection, quality traits and their blast resistance (Table 4). Twenty out of 31 cultivars were Iranian local landraces, most of which were aromatic and long grain.

\section{Disease evaluation at seedling stage}

For evaluation of seedling blast infection, the seeds of each cultivar were sown in blast nursery in 3 replicates in June 2014. Two weeks before that, a mixture of three susceptible local rice cultivars (from Tarom group) as spore spreaders were sown in two rows around the experiment filed. Control experiment with 3 replicates of each cultivar was conducted at a field (isolated by Chaetae barrier of $2.5 \mathrm{~m}$ height) without rows of blast spreader cultivars.

Evaluation of the reaction of cultivars to blast (leaf infection type) was performed 30 days after sowing, based on observed symptoms at leaf surface using the international standard method (IRRI, 2013) by scoring degrees between 0 to 5 , and the genotypes were classified to three infection types so that resistant $(R)=0.0$ to 2.0 ; 
moderately resistant $(\mathrm{MR})=2.1$ to 3.0 and susceptible $(\mathrm{S})=$ 3.1 to 5.0 .

\section{Evaluations at whole plant stage}

For evaluating blast infection of panicles and grains, 21-old seedlings of each cultivar were transplanted in paddy field in 3 replicates. Two rows of blast spreader (seedlings of susceptible cultivars of Tarom group) were transplanted around the experiment filed. Control experiment with 3 replicates of each cultivar was conducted at a field (isolated by Chaetae barrier of $2.5 \mathrm{~m}$ height) without rows of blast spreader cultivars.

After ripening, panicles of each cultivar were visually inspected for blast infection, and rice grains of the studied cultivars were visually evaluated for blast disease severity, and their infection was examined and validated under a light microscope for conidia of $P$. oryzae. Rice grains were analyzed for 100 -grain weight $(\mathrm{g})$ and grain qualities such as percentage of broken rice and number of chalky grains per panicle at the laboratory. For 100 -grain weigh, 3 replicates of 100 seeds were randomly picked up from a large seed batch (at least containing 5000 seeds of each cultivar) and then each replicate was weighted using a digital weighting machine. Similarly, 3 replicates of 100 seeds were hulled, and broken and chalky grains were counted and converted to percentages.

\section{Sampling and DNA extraction}

For DNA extraction, seeds of the studied cultivars were grown in paper filters in growth chamber $\left(28^{\circ} \mathrm{C}\right)$. Leaf samples were collected after 10 days and then grinded using liquid nitrogen to a fine powder. Total DNA was extracted using cetyltrimethyl ammonium bromide (CTAB) method with some modifications (Ahmadikhah, 2009). The quality and quantity of DNA was checked by electrophoresis in $1 \%$ agarose gel and also by spectrophotometer (UV-Visible).

\section{Molecular tests to detect Pi5 and Pi-ta alleles}

One primer pair (Jj80F:5'- TTATGAGATTAGGAGTGTAT-3'; Jj80R: 5'-ATGTAAAGGCAAAAGCTGAT-3') was synthesized for tracking Pi5 locus on chromosome 9 based on $\mathrm{Yi}$ et al. (2004). Pi5-specific band was expected to be 442 bp long, while pi5 allele doesn't produce any band. For tracking Pi-ta locus on chromosome 12 , three primers were synthesized (Table 2) based on Wang et al. (2007). Pita-specific and pitaspecific bands in separate PCR tests were expected to be 1042 and 1043 bp long, respectively. Polymerase chain reaction (PCR) mixture included $5 \mu \mathrm{L}$ of deionized water, 6 $\mu \mathrm{L}$ PCR Master Mix (SinaClone Co.), $0.25 \mu \mathrm{L}$ of each primer $(10 \mathrm{pg})$ and $0.75 \mu \mathrm{L}$ of DNA template $(15 \mathrm{ng})$. Each reaction was prepared in a $0.2-\mathrm{mL}$ tube. The PCR amplification started at $94^{\circ} \mathrm{C}$ for $5 \mathrm{~min}$ and continued for 35 cycles (each cycle consisted of denaturation at $94^{\circ} \mathrm{C}$ for $35 \mathrm{~s}$, annealing at $55^{\circ} \mathrm{C}$ for $30 \mathrm{~s}$, extension at $72^{\circ} \mathrm{C}$ for $1 \mathrm{~min}$ ). Completing the synthesis was done at $72^{\circ} \mathrm{C}$ for $7 \mathrm{~min}$. The PCR products were separated by electrophoresis in $2 \%$ agarose gel and $1 x$ TBE buffer containing $0.5 \mu \mathrm{g} \mathrm{ml}^{-1}$ of ethidium bromide. A molecular size marker (100-1000 bp ladder) was used to determine the fragments sizes. DNA fragment bands became visible after staining by ethidium bromide and their photos were taken under ultraviolet light by a Gel-Doc system (BioRad, USA).

\section{Acknowledgements}

This work is a part of the Project \#90002901 'Transferring of blast disease resistance genes into susceptible cultivars of Khazar region using backcrossing and marker-assisted selection', funded by Iran National Science Foundation (INSF), the Ministry of Science and Technology, I.R. Iran

\section{References}

Abedi F, Babaeiyan N, Moumeni A (2012) Performance of different rice genotypes against blast pathogen through linked molecular markers. J Crop Sci Biotechnol. 15(2): 7984.

Ahmadikhah A (2009) A rapid mini-prep DNA extraction method in rice. Afr J Biotechnol. 8(2): 323-27.

Ahn SN, Kim YK, Hong HC, Han SS, Kwon SJ, Choi HC, Moon HP, McCouch SR (2000) Molecular mapping of a new gene for resistance to rice blast (Pyricularia grisea Sacc.) Euphytica. 116: 17-22.

Barman SR, Gowda M, Venu RC, Chattoo BB (2004) Identification of a major blast resistance gene in the rice cultivar 'Tetep'. Plant Breeding 123(3): 300-302.

Bonman JM (1991) Assessment of blast disease and yield loss in susceptible and partially resistant rice cultivars in two irrigated lowland environments. Plant Dis. 75: 462466.

Bonman, JM (1992) Blast. In: Compendium of rice diseases (Eds. Webster R.K., Gunnell P.S.). Saint Paul, MN, USA, American Phytopathological Society Press.

Bryan GT, Wu KS, Farrall L, Jia Y, Hershey HP, McAdams SA, Valent B (2000) A single amino acid difference distinguishes resistant and susceptible alleles of the rice blast resistance gene Pi-ta. Plant Cell Online. 12(11): 20332045.

Chaudhury B, Karki BP, Lal KK (1994) Neck blast resistant lines of Radha-17 isolated. Int Rice Res Notes. 19: 11.

Flor HH (1956) The complementary genetic systems in flax and flax rust. Adv Genet. 8: 29-54.

Fukuoka S, Okuno K (2001) QTL analysis and mapping of pi21, a recessive gene for field resistance to rice blast in Japanese upland rice. Theor Appl Genet. 103: 185-190.

Gowda M, Barman-Roy S, Chatoo BB (2006) Molecular mapping of a novel blast resistance gene Pi38 in rice using SSLP and AFLP markers. Plant Breeding 125: 596-599.

Hai LH, Kim PV, Du PV, Thuy TTT, Thanh DN (2007) Grain yield and grain-milling quality as affected by rice blast disease (Pyricularia grisea), at My Thanh Nam, Cai Lay, Tien Giang. Omonrice. 15: 102-107.

Han SS (2001) Improvement of disease evaluation system and classification of rice blast isolates. In Proc. 1st Workshop Rice Blast. Milyang, pp. 1-19.

Hayashi K, Hashimoto N, Daigen M, Khanawa I (2004) Development of PCR-based SNP markers for rice blast resistance genes at the Piz locus. Theor Appl Genet. 108: 1212-1220.

He YY, Li J, Li C, Kiyosawa S, Higashi T, Horisue N (1989) Gene analysis of blast resistance of Yunnan upland rice variety, Haonaihuan. Oryza. 26: 173-182. 
Higashi T, Kushibuchi K (1978) Genetic analysis of field resistance to leaf blast (Pyricularia oryzae) in Japan. JPN J Breed. 28: 277-286.

Higashi T, Saito S (1985) Linkage group of field resistance genes upland rice variety Sensho to leaf blast caused by Pyricularia oryzae CAV. JPN J Breed. 35: 438-448.

IRRI (International Rice Research Institute) (2013) SES: standard evaluation system for rice. International Rice Research Institute, Manila, Philippines.

Jia Y, Martin R (2008) Identification of a new locus, Ptr(t), required for rice blast resistance gene $P$ i-ta-mediated resistance. Mol Plant Microbe In. 21: 396-403.

Jia Y, Mcadams SA, Bryan GT, Hershey HP, Valent B (2000) Direct interaction of resistance gene and avirulence gene products confers rice blast resistance. EMBO J. 19: 40044014.

Jia Y, Valent B (2007) Molecular aspects of rice blast resistance: Insights from structural and functional analysis of the Pi-ta and AVR-Pita gene pair. In: Rice improvement in the genomic era. Data, S. (ed.), Baca Raton, FL, CRC Press.

Jia Y, Wang Z, Fjellstrom RG, Moldenhauer KAK, Azam MA, Correll JC, Lee FN, Xia Y, Rutger JN (2004) Rice Pi-ta gene confers resistance to the major pathotypes of the rice blast fungus in the United States. Phytopathology. 94: 296301.

Kawasaki-Tanaka A, Fukuta Y (2014) Genetic variation in resistance to blast disease (Pyricularia oryzae Cavara) in Japanese rice (Oryza sativa L.) as determined using a differential system. Breeding Sci. 64(2): 183-192.

Khan MAI, Sen PP, Bhuiyan MR, Kabir ME, Chowdhury AK, Fukuta Y, Ali MA, Latif MA (2014) Phenotypic screening and molecular analysis of blast resistance in fragrant rice for marker assisted selection. C R Biol. 337: 318-324.

Kiyosawa $S$ (1967) Inheritance of resistance of the rice variety Pi No. 4 to blast. JPN J Breed. 17: 165-172.

Koutroubas SD, Katsantonis D, Ntanos DA, Lupotto E (2009) Blast disease influence on agronomic and quality traits of rice varieties under Mediterranean conditions. Turk J Agric For. 33: 487-494.

Lee SK, Song MY, Seo YS, Kim HK, Ko S, Cao PJ, Jeon JS (2009) Rice Pi5-mediated resistance to Magnaporthe oryzae requires the presence of two coiled-coil-nucleotidebinding-leucine-rich repeat genes. Genetics. 181(4): 16271638.

Li YB, Wu CJ, Jiang GH, Chen HL, He YQ (2008) Dynamic QTL analysis for rice blast resistance under natural infections conditions. Aust J Crop Sci. 2: 73-82.

Li YB, Wu CJ, Jiang GH, Wang LQ, He YQ (2007) Dynamic analysis of rice blast resistance for the assessment of genetic and environmental effects. Plant Breeding. 126: 541-547.

Loan LC, Du PV, Li Z (2003) Identification of genes conferring resistance to some Philippine and Vietnamese races of blast. Omonrice. 11: 49-62.

Maruyama K, Kikuchi F, Yokoo M (1983) Gene analysis of field resistance to rice blast (Pyricularia oryzae) in Rikuto Norin Mochi 4 and its use for breeding. B Natl Agric Sci. 35: 1-31. In Jap.

Moldenhauer KAK, Lee FN, Norman RJ, Helms RS, Well RH, Dilday RH, Rohman PC, Marchetti MA (1990) Registration of 'Katy' rice. Crop Sci. 30: 747-748.
Mousanejad S, Moumeni A, Javan-Nikkhah M (2010) Evaluation of the blast resistance components in some rice cultivars. Iran J Plant Pathol. 46(1): Pe23-Pe36, En9-En10. In Per.

Nagato Y, Yoshimura A (1998) Report of the committee on gene symbolization, nomenclature and linkage group. Rice Genet Newsl. 15: 13-74.

Ou SH (1985) Rice Diseases 1 (2nd ed.). Commonwealth Mycological Institute, Kew, UK.

Pan QH, Hu ZD, Takatoshi T, Wang L (2003) Fine mapping of the rice blast resistance gene Pi15, linked to Pii, on rice chromosome 9. Acta Bot Sin. 45: 871-877.

Pasha A, Babaeian-Jelodar N, Bagheri N, Nematzadeh G (2013) Leaf blast resistance of rice different genotypes in blast nursery. In J Agric Crop Sci. 5(12): 1307.

Rahman L, Khanam S, JaeHwan R (2011) Mapping of QTLs involved in resistence to rice blast (Magnaporthe grisea) using Oryza minuta introgression lines. Czech J Genet Plant. 47(3): 85-94.

Silue D, Nottegherm JL, Tharreau D (1992) Evidence of a gene for-gene relationship in the Oryza sativaMagnaporthe grisea pathosystem. Phytopathology. 82: 577-580.

Wang G, Mackill DJ, Bonman M, Mccouch SR, Champoux MC, Nelson RJ (1994) RFLP mapping of genes conferring complete and partial resistance to blast in a durably resistant rice cultivar. Genetics. 136: 1421-1434.

Wang GL, Mackill DJ, Bonman JM, McCouch SR, Champoux MC, Nelson RJ (1994) RFLP mapping of genes conferring complete and partial resistance to blast in a durably resistance rice cultivar. Genetics. 136:1421-1434.

Wang Z, Jia Y, Rutger JN, Xia Y (2007) Rapid survey for presence of a blast resistance gene Pi-ta in rice cultivars using the dominant DNA markers derived from portions of the Pi-ta gene. Plant Breeding. 126: 36-42.

Wu JL, Fan YY, Li DB, Zheng KL, Leung H, Zhuang JY (2005) Genetic control of rice blast resistance in the durably resistant cultivar Gumei 2 against multiple isolates. Theor Appl Genet. 111: 50-56.

Yi G, Lee SK, Hong YK, Cho YC, Nam MH, Kim SC, Han SS, Wang GL, Hahn TR, Ronald PC, Jeon JS (2004) Use of Pi5(t) markers in marker-assisted selection to screen for cultivars with resistance to Magnaporthe grisea. Theor Appl Genet. 109: 978-985.

Zhou T, Wang Y, Chen JQ, Araki H, Jing Z, Jiang K, Shen J, Tian D (2004) Genome-wide identification of NBS genes in japonica rice reveals significant expansion of divergent non-TIR NBS-LRR genes. Mol Genet Genomics.. 271: 402415. 